\title{
The relationship between nutritional and sociodemographic factors and the likelihood of children in the Dominican Republic having a BCG scar
}

\author{
Eddy Pérez-Then, ${ }^{1}$ Gail Shor-Posner, ${ }^{2}$ Lee Crandall, ${ }^{2}$ and James Wilkinson ${ }^{2}$
}

Puggested citation-Then E, Shor-Posner G, Crandall L, Wilkinson J. The relationship between nutritional and socio-
demographic factors and the likelihood of children in the Dominican Republic having a BCG scar. Rev Panam Salud Publica. 2007;21(6):365-72.

\begin{abstract}
Objectives. To critically assess the prevalence among schoolchildren 6 to 9 years of age throughout the Dominican Republic of a bacille Calmette-Guérin (BCG) vaccination scar, and to examine the relationship between nutritional and sociodemographic factors and the likelihood of having a BCG scar.

Methods. This correlational study used the database of the Second National Census on Height and Weight of Elementary School First Grade Students, which was conducted in the Dominican Republic August 2001-May 2002, to provide a critical assessment of BCG coverage nationwide. The Census information for the children included the presence of BCG scar, their nutritional status, and basic demographic data. We developed a new sociodemographic indicator, the "Rosa Index," to examine the potential influence of poverty and other environmental characteristics on scar presence. We used logistic regression models to predict the presence of a BCG scar.

Results. An overall BCG scar prevalence of 55.3\% (85 644/154 887) was found. Malnourished children were less likely to have a BCG scar than were children with adequate nutritional status (odds ratio $=0.91 ; 95 \%$ confidence interval: $0.87,0.95, \mathrm{P}<0.05$ ). Children who were 7-9 years old were less likely to have a BCG scar than were children 6 years old. Children in the areas of the country more than two hours' driving distance from the capital city of Santo Domingo more often exhibited lower BCG scar prevalence levels than did children in Santo Domingo. A higher Rosa Index (better level of socioeconomic characteristics) was correlated with higher BCG scar prevalence values $(\mathrm{r}=0.54, \mathrm{P}<0.05)$.

Conclusions. Our study findings indicate that BCG coverage appears to be inadequate for schoolchildren in the Dominican Republic. Nevertheless, the presence of a scar in a higher proportion of younger children suggests that coverage has improved in recent years. More programmatic and economic emphasis needs to be placed on extending early BCG vaccination coverage to the areas of the country where vaccination coverage is lower, and on examining the potential role that poverty may have on vaccination effectiveness.
\end{abstract}

Key words Tuberculosis, BCG vaccine, cicatrix, vaccination, population surveillance, socioeconomic factors, Dominican Republic.

National Research Center on Maternal and Child Health (CENISMI), Avenida Abraham Lincoln \#2 Esq. Ave. Independencia, Centro de Los Héroes, Santo Domingo, República Dominicana. Send cor- respondence to: Eddy Pérez-Then; e-mail: ept26@ yahoo.com; telephone: (809) 533-2873; fax: (809) 532-6450.
Department of Epidemiology and Public Health Miller School of Medicine, University of Miami, Miami, Florida, United States of America. 
Bacille Calmette-Guérin (BCG) vaccination has been used to prevent tuberculosis (TB) since 1921, and it was incorporated in the World Health Organization (WHO) Expanded Program on Immunization (EPI) in 1974 to strengthen the fight against childhood TB in developing countries (1-3). Though there are controversies regarding the vaccine's efficacy, it is generally agreed that it is effective against disseminated disease and meningitis in childhood TB (4-7). Favorable outcomes of BCG vaccination have also been reported in the prevention of leprosy (8) and in the treatment of superficial bladder carcinoma (7).

The presence or absence of a BCG scar is often used in clinical settings as an indicator of vaccine effectiveness, and the same is done in surveys carried out by EPI and other health programs in order to assess vaccine uptake (9). However, BCG scar as a measure of vaccine coverage is still a subject of controversy. It has been reported that approximately $10 \%$ of children successfully immunized with BCG don't develop a scar. Discrepancies that are found in vaccine effectiveness can be explained by vaccine characteristics (nonpotent BCG strain dose, or quality), poor vaccination techniques, recipient characteristics (e.g., age at vaccination, immunity and nutritional status, race), and information bias or falsified child records (10).

The Dominican Republic has a high TB incidence rate, approximately 45 cases per 100000 inhabitants (11). BCG vaccination has been carried out in accordance with WHO guidelines, under the aegis of the immunization program of the Ministry of Health. Since 1978, intradermal administration of BCG has been recommended at birth in any hospital, health post, or other health facility. Since 1991, the same strain of BCG has been used across the country (11).

As of 2005, the Dominican health authorities estimated the BCG coverage in children less than 2 years of age to be $98 \%$ (12). Despite this high vaccination rate, and an HIV prevalence among the general population (15-60 years of age) of $1 \%(12)$, the incidence of pediatric tuberculosis meningitis (less than 2 years of age) per 100000 cases in the Dominican Republic increased from 0.1 per 100000 cases in 2004 to 0.7 per 100000 cases in 2005 (11).

This study was conducted to assess nationwide BCG scar prevalence in Dominican children, and it also examined the relationship between nutritional and sociodemographic factors and the likelihood of having a BCG scar.

\section{METHODS}

\section{National Census on Height and Weight of Elementary School First Grade Students}

In August 2001-May 2002, Soriano et al. carried out the Second National Census on Height and Weight of Elementary School First Grade Students (II Censo Nacional de Talla y Peso en Escolares de Primer Grado de Básica) in the Dominican Republic (13). All children from 6 to 9 years of age attending public or private elementary school were included in the Census on Height and Weight. A trained school teacher interviewed the caregivers of the children, who accompanied the children to the school. The interviews typically lasted 30 minutes and were performed in a private classroom in the school.

A pretest was conducted with 50 schoolchildren from the different school regions of the Dominican Republic. (There are 16 school regions in the Dominican Republic, with each region comprised of different provinces and municipalities (Figure 1). The school regions were created by the Secretariat of Education to facilitate logistics (food distribution, data collection, etc.) among rural and urban areas of the country). As part of the training procedures, school teachers were instructed on how to recognize the BCG scar, perform anthropometric measures, and conduct the interviews. Methods were standardized for filling out and reviewing the study forms.

The teacher interviewers were trained to obtain measurements of height, using standard anthropometric methods. Height was calculated with a locally made centimeter measuring board placed on the wall at a 90degree angle, as recommended by the Pan American Health Organization.

The interviewer examined both of the child's arms for the presence of a BCG scar and recorded the scar's presence or absence on a data collection form. Basic demographic data (age, sex, and place of residence (school region)) of the subject were obtained, as well as information about the legal guardian's socioeconomic status. Information about the school building, such as type of toilet, trash collection, and type of construction (wood or cement), was also collected, and recorded on the data collection form.

The Census on Height and Weight data included the prevalence of malnutrition by school region. To estimate nutritional parameters (height-forage), percentiles were calculated using the United States National Center for Health Statistics tables with $<2$ standard deviations as the cutpoint for malnutrition estimators.

\section{A secondary data analysis of the BCG scar prevalence in Dominican children}

This research was a correlational, secondary data analysis study intended to determine the effect of sociodemographic and nutritional parameters on the likelihood of having BCG scar.

We performed the statistical analysis of the collected data using SPSS 11.5 (SPSS, Chicago, Illinois, United States of America) and NCSS 2004 and PASS 2002 (NCSS, Kaysville, Utah, United States). BCG prevalence proportions were calculated, and the effects of the study variables (basic demographic data, residence of the subject, and nutritional indicators) on the likelihood of vaccination (as indicated by the scar's presence) were estimated by means of odds ratios (ORs) and $95 \%$ confidence intervals (95\% CIs), obtained through logistic regression, employing univariate and multi- 
FIGURE 1. BCG scar prevalence among schoolchildren in the Dominican Republic, by school region, 2001-2002

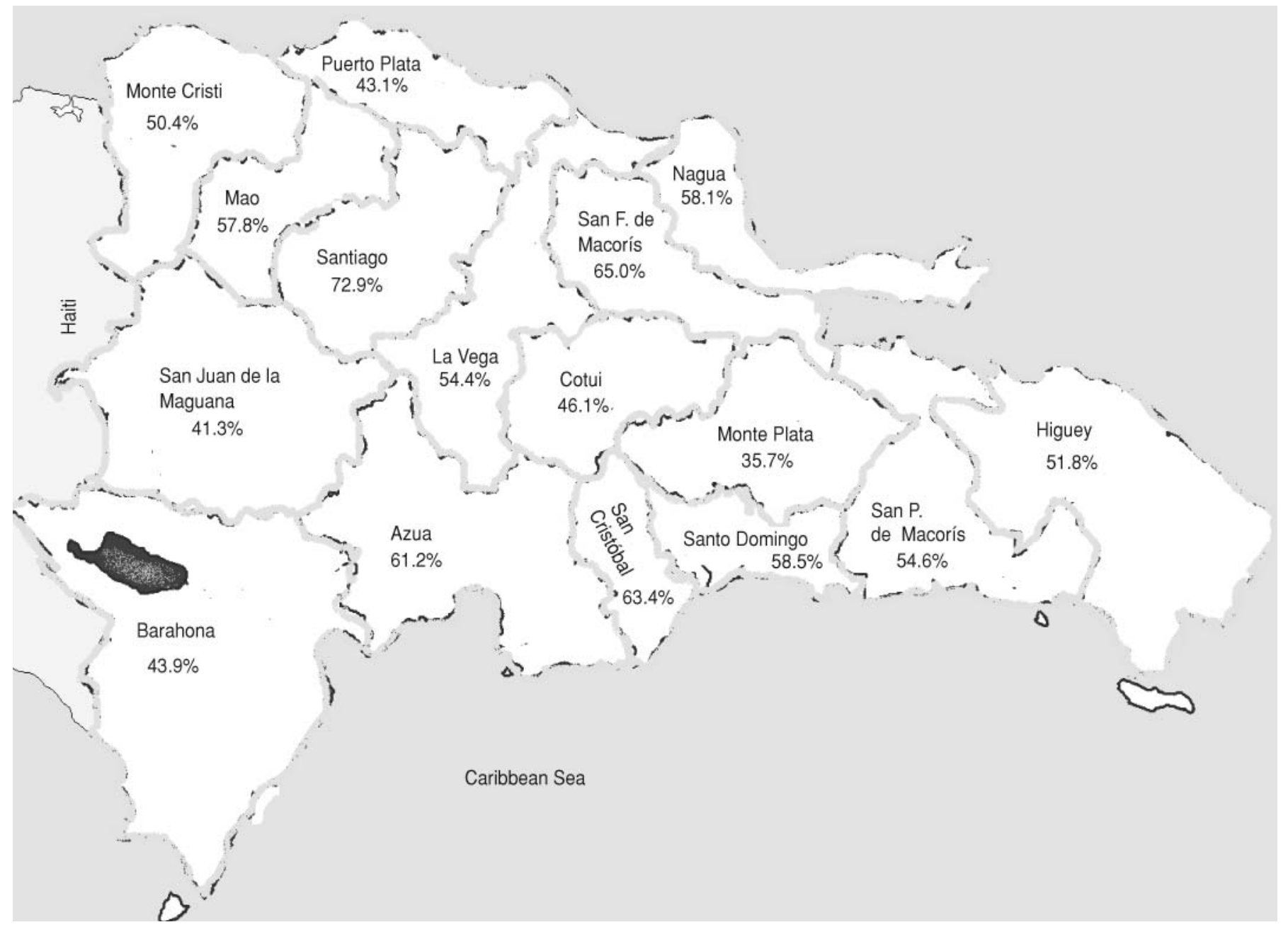

variate analyses (14). Logistic regression models were also developed to predict the presence of a BCG scar. In each model, the category most positively associated with the presence of BCG scar was generally used as the reference category.

To facilitate interpretation of the school data for univariate and multivariate models, the school regions were grouped into three geographic categories: (1) Santo Domingo (reference group), which is the capital of the Dominican Republic; (2) school regions one to two hours' driving distance from the capital ("Mid School Regions"); and (3) school regions more than two hours' driving distance from the capital ("Other School Regions").
The Rosa Index. To evaluate the impact of sociodemographic ecological variables on scar presence, a new quantitative sociodemographic indicator, the "Rosa Index," was developed by the main author (E. Pérez-Then) in collaboration with Rosa Urania Abreu and the authors of the Census on Height and Weight. (The term "Rosa" was used to acknowledge the contribution of Rosa Urania Abreu in developing the index.) This new approach assigned a possession score to every school region based on the mean values of monthly household income, as well as the mean proportional values of residential and schools characteristics for each region. The Rosa Index values were assigned according to the sociodemographic data collected in the Census on Height and Weight in August 2001-May 2002. Possible index scores could range from zero (minimum) to 12 (maximum). The higher the index score, the better the "ecological" characteristics of the school region. The Rosa Index was also included in a multivariate model to predict the presence of BCG scar in Dominican children.

Multivariate analysis. For the multivariate analysis, variables were entered according to their statistical significance (in univariate analysis) and their biologic relevance. Various models were evaluated, including a full model containing all the variables 
studied, in order to select the best possible model to fit the data. The goodness of fit of the logistic models was assessed taking into consideration the changes introduced into the log likelihood function. Alpha was set at 0.05.

Ethical issues. Ethical approval for the study was obtained, in the Dominican Republic, from the Human Research Subject Committee of the Centro $\mathrm{Na}$ cional de Investigaciones en Salud Materno Infantil (CENISMI) (National Research Center on Maternal and Child Health), and, in the United States, from the Institutional Review Board of the University of Miami.

\section{RESULTS}

\section{BCG scar prevalence}

The overall BCG scar prevalence found through the examination of the children's arms was 55.3\% (85 644/ $154887)$.

\section{Sociodemographic characteristics and BCG scar presence}

The characteristics of the children are shown, by gender, in Table 1 . There was a similar presence of BCG scar among males and females. Statistically significant gender differences were found for nutritional status and age $(P<0.05)$.

\section{Univariate analysis}

The univariate analysis showed associations between several variables and the presence of BCG scar (Table 2). Malnourished children were less likely to have BCG scar than were children in the reference group $(\mathrm{OR}=0.91 ; 95 \%$ $\mathrm{CI}=0.87,0.95)$. Age was also an indicator, with children 7-9 years old being less likely to have a BCG scar than were children 6 years old (the reference group for age) $(P<0.05)$.

Another factor that was associated with scar presence was geographic location (Table 2). In general, children

TABLE 1. Scar prevalence, nutritional status, age, and place of residence (school region), by gender, in study of BCG scar prevalence, Dominican Republic, 2001-2002

\begin{tabular}{|c|c|c|c|c|}
\hline \multirow[b]{2}{*}{ Variable } & \multicolumn{2}{|c|}{ Males } & \multicolumn{2}{|c|}{ Females } \\
\hline & $\mathrm{No}^{\mathrm{a}}$ & $\%$ & No. ${ }^{a}$ & $\%$ \\
\hline \multicolumn{5}{|l|}{ BCG scar } \\
\hline Yes & 45567 & 55.3 & 40077 & 55.3 \\
\hline No & 36826 & 44.7 & 32417 & 44.7 \\
\hline \multicolumn{5}{|l|}{ Nutritional status ${ }^{b}$} \\
\hline Malnutrition & 6568 & 7.4 & 4015 & 5.5 \\
\hline Adequate & 82393 & 92.6 & 68479 & 94.5 \\
\hline \multicolumn{5}{|l|}{ Age $(y r)^{\mathrm{b}}$} \\
\hline 6 & 34838 & 45.7 & 34083 & 50.8 \\
\hline 7 & 24633 & 32.2 & 21246 & 31.7 \\
\hline 8 & 11469 & 15.0 & 8158 & 12.2 \\
\hline 9 & 5512 & 7.2 & 3626 & 5.4 \\
\hline \multicolumn{5}{|l|}{ Place of residence (school region) } \\
\hline Santo Domingo (capital) & 14389 & 17.5 & 13030 & 18.5 \\
\hline \multicolumn{5}{|l|}{ Mid School Regions ${ }^{c}$} \\
\hline Santiago & 7391 & 8.9 & 6816 & 9.4 \\
\hline La Vega & 7228 & 8.8 & 6101 & 8.4 \\
\hline Azua & 6319 & 7.7 & 5545 & 7.7 \\
\hline San Cristóbal & 5663 & 6.9 & 5062 & 6.9 \\
\hline San Pedro de Macorís & 5735 & 6.9 & 5003 & 6.9 \\
\hline Monte Plata & 1908 & 2.3 & 1577 & 2.2 \\
\hline \multicolumn{5}{|l|}{ Other School Regions ${ }^{d}$} \\
\hline San Juan de La Maguana & 5148 & 6.3 & 4421 & 6.1 \\
\hline Barahona & 4879 & 5.9 & 4497 & 6.2 \\
\hline San Francisco de Macorís & 4424 & 5.4 & 3743 & 5.2 \\
\hline Cotui & 4151 & 5.0 & 3464 & 4.8 \\
\hline Puerto Plata & 3678 & 4.5 & 3428 & 4.7 \\
\hline Higuey & 3194 & 3.9 & 2751 & 3.8 \\
\hline Nagua & 3275 & 3.9 & 2721 & 3.8 \\
\hline Monte Cristi & 2530 & 3.1 & 2123 & 2.9 \\
\hline Mao & 2346 & 2.9 & 2104 & 2.9 \\
\hline
\end{tabular}

a Total sample size is different for each variable (e.g., scar, nutritional status, age, and place of residence).

${ }^{b} P<0.05$. For nutritional status: odds ratio $=1.36 ; 95 \%$ confidence interval: $1.3,1.4, P<0.05$. For age: $\chi^{2}=601, P<0.0001$.

'The Mid School Regions are ones that are one to two hours' driving distance from the capital, Santo Domingo.

'Other School Regions are ones that are more than two hours' driving distance from the capital, Santo Domingo.

living in Mid School Regions (less than two hours' driving distance from the capital) were more likely to have a BCG scar than were children living in Santo Domingo, the capital of the Dominican Republic (reference category). In contrast, children living in the Other School Regions (more than two hours' driving distance from the capital) were generally less likely to present a scar than were children living in Santo Domingo (Table 2).

\section{Multivariate analysis}

The multivariate analysis used a full three-model variable since removal of each of the variables did not result in a different and significantly improved pattern to fit the data. The multivariate analysis revealed the same pattern of significance observed in the univariate analysis, except for nutritional status, which no longer had a statistically significant affect on the scar's presence.

\section{The Rosa Index}

To further elucidate variance in the likelihood of having a BCG scar, the Rosa Index was used (Table 3). The Rosa Index evaluated the impact of 12 environmental variables (residence characteristics and school characteristics) on scar prevalence. The highest score for a particular school region could be 12 points, and the lowest could be zero. The higher the Rosa 
TABLE 2. Nutritional status, age, and place of residence (school region), by BCG scar prevalence and univariate odds ratio, with $95 \%$ confidence interval (Cl), Dominican Republic, 2001-2002

\begin{tabular}{|c|c|c|c|c|}
\hline Characteristic & $\begin{array}{c}\text { No. } \\
\text { positive/total }\end{array}$ & $\begin{array}{c}\text { BCG scar } \\
(\%)\end{array}$ & $\begin{array}{l}\text { Odds } \\
\text { ratio }\end{array}$ & $95 \% \mathrm{Cl}$ \\
\hline \multicolumn{5}{|l|}{ Nutritional status ${ }^{\mathrm{a}}$} \\
\hline Adequate ${ }^{b}$ & $80755 / 145462$ & 55.5 & 1.00 & \\
\hline Malnutrition & $5627 / 10583$ & 53.2 & 0.91 & $0.87,0.95$ \\
\hline \multicolumn{5}{|l|}{ Age $(y r)^{a}$} \\
\hline $6^{b}$ & $40453 / 69328$ & 58.4 & 1.00 & \\
\hline 7 & $24900 / 46209$ & 53.9 & 0.75 & $0.73,0.78$ \\
\hline 8 & 10 176/19 799 & 51.4 & 0.73 & $0.71,0.75$ \\
\hline 9 & $4461 / 9204$ & 48.5 & 0.67 & $0.64,0.70$ \\
\hline \multicolumn{5}{|l|}{ Place of residence (school region) } \\
\hline Santo Domingo (capital) ${ }^{\mathrm{b}}$ & $16129 / 27553$ & 58.5 & 1.00 & \\
\hline \multicolumn{5}{|l|}{ Mid School Regions ${ }^{c}$} \\
\hline Santiago ${ }^{a}$ & $9845 / 13503$ & 72.9 & 1.53 & $1.46,1.59$ \\
\hline San Cristóbala & $6824 / 10764$ & 63.4 & 1.23 & $1.17,1.28$ \\
\hline Azua $^{\mathrm{a}}$ & 7 284/11 898 & 61.2 & 1.12 & $1.07,1.17$ \\
\hline San Pedro de Macorís ${ }^{\mathrm{a}}$ & $5934 / 10874$ & 54.6 & 0.85 & $0.81,0.89$ \\
\hline La Vega ${ }^{a}$ & $7279 / 13384$ & 54.4 & 0.84 & $0.81,0.88$ \\
\hline Monte Plata ${ }^{a}$ & $1256 / 3516$ & 35.7 & 0.39 & $0.37,0.42$ \\
\hline \multicolumn{5}{|l|}{ Other School Regions ${ }^{d}$} \\
\hline San Francisco de Macorís ${ }^{a}$ & $5341 / 8212$ & 65.0 & 1.32 & $1.25,1.39$ \\
\hline Nagua & $3529 / 6069$ & 58.1 & 0.98 & $0.93,1.04$ \\
\hline Mao & $2576 / 4454$ & 57.8 & 0.97 & $0.91,1.04$ \\
\hline Higuey $^{a}$ & $3121 / 6026$ & 51.8 & 0.76 & $0.72,0.81$ \\
\hline Monte Cristia & $2346 / 4659$ & 50.4 & 0.72 & $0.67,0.76$ \\
\hline Cotui $^{\mathrm{a}}$ & $3571 / 7744$ & 46.1 & 0.61 & $0.58,0.64$ \\
\hline Barahona $^{a}$ & 4 134/9 421 & 43.9 & 0.59 & $0.56,0.63$ \\
\hline Puerto Plata ${ }^{a}$ & 3 085/7 154 & 43.1 & 0.54 & $0.51,0.57$ \\
\hline San Juan de La Maguana ${ }^{a}$ & $3985 / 9656$ & 41.3 & 0.50 & $0.47,0.52$ \\
\hline
\end{tabular}

a $P<0.05$.

${ }^{b}$ Reference group.

c The Mid School Regions are one to two hours' driving distance from the capital, Santo Domingo.

d The Other School Regions are ones that are more than two hours' driving distance from the capital, Santo Domingo.

Index score, the better were the "ecological" characteristics of the school region. The correlation between the Rosa Index scores and the BCG scar prevalences for the school regions was statistically significant $(r=0.54, P<0.05)$.

When the Rosa Index was included in the multivariate model (Table 4), nutritional status was reduced in significance $(P=0.052)$, and the subjects' age and the Rosa Index were independently associated with the presence of BCG scar $(P<0.05)$. Elevated Rosa Index scores were found in school regions with higher BCG scar prevalence values.

\section{DISCUSSION}

Our analysis of the data from the Census on Height and Weight indi- cates that a large proportion of the Dominican children aged 6-9 years old did not appear to have been vaccinated against TB.

Several factors appeared to contribute to the lack of BCG scar presence. Malnourished children were less likely to have a BCG scar than were children with adequate nutritional status, suggesting that population groups with better nutritional status may have a stronger response to BCG vaccine, or that poorer children may have been less likely to be vaccinated and/or immunized. In evaluating these findings, it is worth recalling common limitations of correlational studies, particularly the inability to link exposure with disease in particular individuals (15). The higher likelihood of malnourished children lacking a BCG scar raises the possibility that malnutrition negatively affects scar development through its impact on the immune system (16). However, from our study, it was not possible to determine the schoolchildren's nutritional status in infancy or to ascertain if there was a relationship between this variable and the presence of a BCG scar. This highlights the importance of obtaining information regarding vaccination history in future census programs implemented in the Dominican Republic.

A second major limitation is related to the representation of average exposure levels, rather than actual individual values. Thus, while it may appear from correlational data that there is an overall positive or negative association, this might actually be masking a more complicated relationship between exposure and disease (15), in this particular case, vaccine administration and the presence of BCG scar. Therefore, in this type of study design, malnutrition should be considered as an indicator of health inequalities rather than as a disturbance in a particular individual's immune system.

The univariate and multivariate analyses indicate an interesting age-related pattern. Children from 7 through 9 years of age were less likely to have the BCG scar than were children 6 years of age. To some extent this may reflect changes in the quality of the BCG vaccination program (e.g., periods of high and low coverage) caused by such factors as vaccine storage conditions and vaccine availability $(17,18)$. The higher proportion of young children with a BCG scar may also reflect a general improvement in vaccination coverage. Other factors at the individual or programmatic level could also be associated with this trend, and they need to be considered in future studies, in which the unit of analysis should be students, and not school regions.

There were also statistical differences in scar prevalence according to geographical location (school region). Better access to the health care services in urban areas, greater availability of pediatricians, and inability of the Dominican EPI to cover all regions of the country, especially the very poor regions along the border with 
TABLE 3. Factors and their point value for the Rosa Index possession score used to categorize school regions in the Dominican Republic according to the characteristics of the homes and the schools in each of the school regions, 2001-2002 ${ }^{\mathrm{a}}$

\begin{tabular}{|c|c|c|c|}
\hline \multirow[b]{2}{*}{ Factor } & \multicolumn{3}{|c|}{ Points } \\
\hline & 0 & 0.5 & 1.0 \\
\hline \multicolumn{4}{|l|}{ House characteristics } \\
\hline Monthly household income (< US\$ 83) & $>80 \%$ & $50 \%-80 \%$ & $<50 \%$ \\
\hline Homeownership & $<35 \%$ & $35 \%-60 \%$ & $>60 \%$ \\
\hline Poor quality of the house & $>50 \%$ & $35 \%-50 \%$ & $<35 \%$ \\
\hline Source of water is tap in the house & $<40 \%$ & $40 \%-65 \%$ & $>65 \%$ \\
\hline Flush toilet in the house & $<10 \%$ & $10 \%-20 \%$ & $>20 \%$ \\
\hline Trash collection (public/government) & $<25 \%$ & $25 \%-40 \%$ & $>40 \%$ \\
\hline Electricity & $<50 \%$ & $50 \%-80 \%$ & $>80 \%$ \\
\hline Stove & $<60 \%$ & $60 \%-80 \%$ & $>80 \%$ \\
\hline \multicolumn{4}{|l|}{ School characteristics } \\
\hline School with good (cement) construction & $<25 \%$ & $25 \%-40 \%$ & $>40 \%$ \\
\hline Flush toilet in the school & $<25 \%$ & $25 \%-40 \%$ & $>40 \%$ \\
\hline Trash collection for the school (public/government) & $<20 \%$ & $20 \%-35 \%$ & $>35 \%$ \\
\hline School receives food ${ }^{b}$ & $>70 \%$ & $50 \%-70 \%$ & $<50 \%$ \\
\hline \multicolumn{4}{|c|}{$\begin{array}{l}\text { a Using the Rosa Index approach, a total possession score was assigned to each school region based on points given for the } \\
\text { mean value of monthly household income for the region as well as the residential characteristics and the school characteris- } \\
\text { tics for each region. For example, a score of } 0 \text { points was given to a particular school region if more than } 80 \% \text { of the resi- } \\
\text { dents reported having a monthly household income of less than US\$ } 83 \text { (using the } 2002 \text { US } \$ \text { exchange rate in the Domini- } \\
\text { can Republic). In contrast, a score of } 1 \text { point was given to a particular school region if more than } 60 \% \text { of the residents reported } \\
\text { homeownership. The highest score for a particular school region could be } 12 \text { points, and the lowest could be zero. The higher } \\
\text { the Rosa Index score was, the better were the "ecological" characteristics of the school region. } \\
\text { b The poorest areas were prioritized to receive food (breakfast) from the government. }\end{array}$} \\
\hline
\end{tabular}

TABLE 4. Adjusted odds ratio and $95 \%$ confidence interval (Cl) from multivariate logistic regression predicting the presence of BCG scar, including the Rosa Index in the model, Dominican Republic, 2001-2002

\begin{tabular}{lccc}
\hline Predictor variable & Odds ratio & $95 \% \mathrm{Cl}$ & $P$ \\
\hline $\begin{array}{l}\text { Nutritional status } \\
\quad \text { Adequate }\end{array}$ & & & \\
$\quad$ Malnutrition & 1.00 & & \\
Age $(\mathrm{yr})$ & 0.96 & $0.92,1.00$ & 0.052 \\
$6^{\mathrm{a}}$ & & & \\
7 & 1.00 & $0.84,0.88$ & 0.02 \\
8 & 0.86 & $0.77,0.82$ & 0.03 \\
9 & 0.79 & $0.72,0.78$ & 0.03 \\
Rosa Index score & 0.75 & $1.10,1.12$ & 0.02 \\
\hline a Reference group. & 1.11 & & \\
b The highest Rosa Index score, 11, was for the Santo Domingo school region, which was the ref- \\
erence group.
\end{tabular}

Haiti (17), may also have contributed to this pattern.

BCG coverage in Santo Domingo, the capital, was expected to be higher than in other areas of the country since a variety of factors affecting the probability of being vaccinated, including better socioeconomic conditions and improvements in public health policies, are present in this area. However, amined in this study and that will need to be considered in future research.

To increase understanding of other variables that could be impacting coverage, the Rosa Index, which included more "ecological" variables, was created. Our results indicate a relatively strong correlation between BCG scar prevalence and the Rosa Index $(r=$ $0.54)$, suggesting that BCG prevalence could be related to factors impacted by poverty and other environmental characteristics. Nutritional status was only significant when the Rosa Index was included in the multivariate model. There was a positive correlation pattern between BCG scar prevalence and the Rosa Index, with the school regions with a higher Rosa Index score having a higher BCG scar prevalence. This finding suggests a potential role for poverty in vaccination effectiveness.

It is important to note that a number of factors that were not represented in the Rosa Index could have had an important impact on scar presence. These factors include the type of legal guardian (mother vs. stepmother, father, etc.), legal guardian's education, legal guardian's employment status, child's history of BCG vaccination, and child's birthplace (home, rural clinic, private clinic, etc.). Future census work in the Dominican Republic will need to evaluate multiple ecological factors in order to provide a broad perspective.

This was a population-based study, and the rate of attendance in the Dominican Republic for children in elementary school is $99 \%$ (19). Consequently, the findings represent Dominican children between 6 and 9 years of age among different school regions of the country. The findings also overcome the limitations reported in previous, hospital-based surveys of BCG coverage implemented in the Dominican Republic $(17,18)$. Nevertheless, we recognize that including additional variables related to EPI logistical procedures, children of different ages (e.g., newborn, infants), and household sociodemographic conditions could increase the predictive value of the statistical models for the 
presence of BCG scar, and might provide a more thorough explanation for the vaccine coverage levels.

In summary, it appears that an appropriate goal for the Dominican health authorities would be to ensure that all children receive the protection afforded by the BCG vaccine. The Census on Height and Weight could be an important tool to monitor coverage not only with BCG vaccine but also with other vaccines in the Dominican EPI. The effectiveness of the Dominican EPI interventions needs to be monitored and to be measured in terms of community perceptions on such priorities as access to health care facilities and vaccine availability. Otherwise, community "ownership" of the EPI efforts is unlikely, and it is doubtful that the EPI objectives will be achieved, even though health care services are, in principle, available. Qualitative surveys could be included in the Census on Height and Weight, in order to learn what caregivers perceive as their priorities for increasing vaccination coverage, how vaccination programs fit into these priorities, and how the perceived priorities could be achieved within the context of the existing constraints such as poorer access to the health care services in rural areas and the inability of the Dominican EPI to cover the very poor regions of the country.

Acknowledgments. This research was supported by a United States National Institutes of Health Fogarty International Center research and training grant on HIV/AIDS and TB (D43-TW000017-17). The authors thanks Dr. John Lewis for his statistical advice, and Dr. Jeannette Báez and Mélida Pérez for data management and programming. The authors also acknowledge the invaluable contribution of Rosa Urania Abreu in the creation of the Rosa Index, and Belkis Cuello for all her support.

\section{REFERENCES}

1. Lugosi L. Theoretical and methodological aspects of BCG vaccine from the discovery of Calmette and Guérin to molecular biology. A review. Tuber Lung Dis. 1992;73:252-61.

2. Fine PEM. BCG vaccination against tuberculosis and leprosy. Br Med Bull. 1988;44(3): 704-16.

3. Smith PG. Case-control studies of the efficacy of BCG against tuberculosis. In: International Union Against Tuberculosis, ed. Proceedings of the XXVIth IUAT World Conference on Tuberculosis and Respiratory Diseases. Singapore: Professional Postgraduate Services International; 1987. Pp. 73-9.

4. Camargos PAM, Guimaraes MDC, Antunes CMF. Risk assessment for acquiring meningitis tuberculosis among children not vaccinated with BCG: a case-control study. Int J Epidemiol. 1988;47(1):193-7.

5. Myint TT, Win H, Aya HH, Kyaw-Mint TO. Case-control study on evaluation of BCG vaccination of newborns in Rangoon, Burma. Ann Trop Paediatr. 1987;7(2):159-66.

6. Bannon MJ. BCG and tuberculosis. Arch Dis Child. 1999;80:80-3.

7. Wang L, Turner MO, Elwood RK, Schulzer M, Fitzgerald JM. A meta-analysis of the effect of Bacille Calmette Guérin vaccination on tuberculin skin test measurements. Thorax. 2002;57:804-9.

8. Zodpey SP, Ambadekar NN, Thakur A. Effectiveness of Bacillus Calmette Guérin (BCG) vaccination in the prevention of leprosy: a population-based case-control study in Yavatmal District, India. Public Health. 2005;119(3):209-16.

9. World Health Organization. Expanded Programme on Immunization. Programme review. Wkly Epidemiol Rec. 1994;69(12):87-90.

10. Santiago EM, Lawson E, Gillenwater K, Kalangi S Lescano AG, Du Quella G, et al. A prospective study of bacillus CalmetteGuerin scar formation and tuberculin skin test reactivity in infants in Lima, Peru. Pediatrics. 2003;112:e298-e302.

11. República Dominicana, Secretaría de Estado de Salud Pública y Asistencia Social, División Nacional de Epidemiología, Programa Nacional de Control de la Tuberculosis. Estadísticas sobre tuberculosis. Santo Domingo: Secretaría de Estado de Salud Pública y Asistencia Social; 2005.

12. Centro de Estudios Sociales y Demográficos, Secretaría de Estado de Salud Pública y Asistencia Social, Comisión Ejecutiva para la Reforma del Sector Salud, Consejo Presidencial del SIDA, Agencia de los Estados Unidos para el Desarrollo Internacional, Banco Mundial/CERSS, Banco Interamericano de Desarrollo/CERSS, Programa MEASURE DHS+/ORC Macro. Encuesta Demográfica y de Salud 2002. Santo Domingo: MEASURE DHS+/ORC Macro: 2003.

13. Soriano G, Chahín D, Báez J. II Censo Nacional de Talla y Peso en Escolares de Primer Grado de Básica, República Dominicana, 2001-2002. Santo Domingo: Centro Nacional de Investigaciones en Salud Materno Infantil,
Secretaría de Estado de Educación, Banco Mundial; 2002.

14. Tabachnick BG, Fidell LS. Using multivariate statistics. 4th edition. Boston: Allyn and Bacon; 2001.

15. Hennekens $\mathrm{CH}$, Buring JE. Epidemiology in medicine. Philadelphia: Lippincott Williams \& Wilkins; 1987.

16. Moore SE, Goldblatt, D, Bates CJ, Prentice AM. Impact of nutritional status on antibody responses to different vaccines in undernourished Gambian children. Acta Paediatr. 2003; 92(2):170-6.

17. Espinal MA, Cruz-Bello J, Pérez EN, Marranzini B. A hospital-based survey of BCG coverage in Santo Domingo, the Dominican Republic. Bull Pan Am Health Organ. 1994; 28(1):1-8.

18. Pérez-Then E, Shor-Posner G, Campa A, Cedano J, Garrido C, Liz V. Cobertura de BCG en dos hospitales pediátricos de referencia nacional en Santo Domingo, República Dominicana. Bol CENISMI. 2001;11(2):15-6.

19. República Dominicana, Oficina Nacional de Estadística. Resultados definitivos. VIII Censo de Población y Vivienda 2002. Vol. IV: Características educativas. Santo Domingo: ONE; 2004.

Manuscript received 17 November 2005. Revised manuscript accepted for publication 5 June 2007. 
RESUMEN Objetivos. Evaluar críticamente la prevalencia de cicatrices por la vacunación con el bacilo de Calmette-Guérin (BCG) en niños de 6 a 9 años de la República Dominicana y examinar la relación entre los factores nutricionales y socioeconómicos y la proba-

\section{Relación entre los factores nutricionales y sociodemográficos y la probabilidad de que los niños de la República Dominicana tengan cicatriz de BCG}

Palabras clave bilidad de tener cicatriz de BCG.

Métodos. Para este estudio correlacional se empleó la base de datos del II Censo Nacional de Talla y Peso en Escolares de Primer Grado de Básica, realizado en la República Dominicana entre agosto de 2001 y mayo de 2002, para evaluar críticamente el nivel de cobertura nacional de la vacunación con BCG. Entre la información censal de los niños estaban si tenían cicatriz de BCG, su estado nutricional y sus datos demográficos básicos. Se desarrolló un nuevo indicador sociodemográfico, el "índice de Rosa", para analizar la posible influencia de la pobreza y de otras características ambientales en la presencia de esa cicatriz. Se emplearon modelos de regresión logística para predecir la presencia de la cicatriz de BCG.

Resultados. La prevalencia general de cicatrices de BCG fue de 55,3\% (85 644/ 154 887). Los niños desnutridos presentaron una menor probabilidad de tener cicatriz de BCG que los niños con un adecuado estado nutricional (razón de posibilidades = 0,91; intervalo de confianza de 95\%: 0,87 a 0,95; $P<0,05)$. Los niños de $7-9$ años tuvieron menor probabilidad de tener cicatriz de BCG que los niños de 6 años. Los niños de zonas del país que se encuentran a más de dos horas de viaje de Santo Domingo, la capital, presentaron menor prevalencia de cicatrices de BCG con mayor frecuencia que los niños de Santo Domingo. Se encontró correlación entre tener un mayor índice de Rosa (mejor nivel en las características socioeconómicas) y una mayor prevalencia de cicatrices de BCG $(r=0,54 ; P<0,05)$.

Conclusiones. Los resultados del presente estudio indican que la cobertura de vacunación de escolares con la vacuna BCG parece no ser la adecuada en la República Dominicana. Sin embargo, la presencia de la cicatriz de BCG en una mayor proporción de niños más pequeños puede indicar que esa cobertura ha mejorado en años recientes. Se debe hacer un mayor énfasis programático y económico para extender la vacunación temprana con BCG a las áreas del país donde la cobertura de vacunación es menor y para analizar el papel que puede estar desempeñando la pobreza en la eficacia de la vacunación.

Tuberculosis, vacuna BCG, cicatriz, vacunación, vigilancia de la población, factores socioeconómicos, República Dominicana.

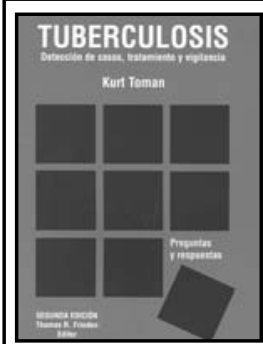

$2006,396 \mathrm{pp}$

ISBN: 9275316171

US $\$ / 24.00$ en países de América Latina y el
Caribe/US\$ 32.00 en el resto del mundo

Código: PC 617

\section{TUBERCULOSIS. Detección de casos, tratamiento y vigilancia}

La segunda edición de este libro de referencia práctico y con información fidedigna proporciona una base racional para el diagnóstico y tratamiento de la tuberculosis. Escrito por varios expertos en el campo, sigue siendo fiel al original de Kurt Toman con un formato de preguntas y respuestas y los capítulos agrupados en tres secciones: detección de casos, tratamiento y vigilancia.

Adquiera esta publicación por medio de la librería en línea de la OPS:

http://publications.paho.org; fax: (301) 206-9789; correo electrónico: paho@pmds.com; OPS/OMS oficina de país 